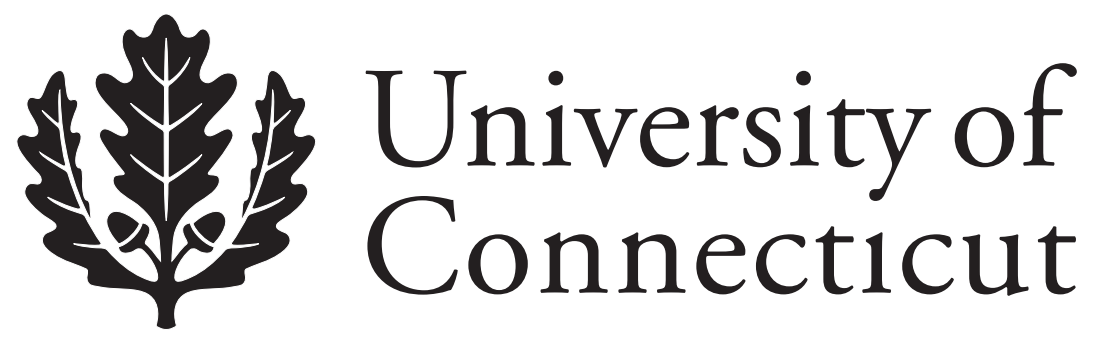

Department of Economics Working Paper Series

MBA Program Reputation And Quantitative Rankings: New Information for Students, Employers, And Program Administrators

Yongil Jeon

Sungkyunkwan University

Stephen M. Miller

University of Nevada, Las Vegas, and University of Connecticut

Subhash C. Ray

University of Connecticut

Working Paper 2007-44

October 2007

341 Mansfield Road, Unit 1063

Storrs, CT 06269-1063

Phone: (860) 486-3022

Fax: (860) 486-4463

http://www.econ.uconn.edu/

This working paper is indexed on RePEc, http://repec.org/ 


\begin{abstract}
Since 1988, Business Week biennially ranks MBA programs based on qualitative ("subjective") surveys of students and employers. The Business Week ranking, and similar rankings, based on perceptions of MBA-program customers, rings the alarm that image, rather than substance, may become the raison detre of MBAprogram evaluation and selection. We rank MBA programs using the quantitative ("objective") data collected with the 2004 Business Week survey, attempting to address these concerns about image over substance. We employ equal-weighted and principal components indexes to rank MBA programs. Our indexes fall into three categories - output, input, and output-input indexes - that rank MBA programs proximately from the interests of students, employers, and MBA program administrators, respectively.
\end{abstract}

Journal of Economic Literature Classification: M00

Keywords: MBA Programs, Reputation, Ranking, Principal Component

This paper updates analysis contained in 
index and using the more recent 2004 Business Week survey. 


\title{
MBA Program Reputation And Quantitative Rankings: New Information for Students, Employers, And Program Administrators
}

October 2007

\begin{abstract}
Since 1988, Business Week biennially ranks MBA programs based on qualitative ("subjective”) surveys of students and employers. The Business Week ranking, and similar rankings, based on perceptions of MBA-program customers, rings the alarm that image, rather than substance, may become the raison d'etre of MBA-program evaluation and selection. We rank MBA programs using the quantitative ("objective”) data collected with the 2004 Business Week survey, attempting to address these concerns about image over substance. We employ equal-weighted and principal components indexes to rank MBA programs. Our indexes fall into three categories - output, input, and output-input indexes - that rank MBA programs proximately from the interests of students, employers, and MBA program administrators, respectively.
\end{abstract}

Keywords: $\quad$ MBA Programs, Reputation, Ranking, Principal Component

JEL Classification: M00 


\section{MBA Program Reputation And Quantitative Rankings: New Information for Students, Employers, And Program Administrators}

\section{Introduction}

Since 1988, Business Week biennially ranks the top business schools in the U.S. This ranking reflects survey questionnaire responses from corporate recruiters, on the one hand, and current and recent graduates, on the other. The reported rankings combine the raw scores of these two sets of survey responses to generate an overall index (ranking). ${ }^{1}$ Apart from enhancing the prestige of individual MBA programs, this ranking can significantly influence popular perception about the quality of the MBAs from different schools and, thus, affect their starting salaries. While the survey results rely on qualitative (“subjective”) information, Business Week reports quantitative (“objective”) information as well. ${ }^{2}$

Qualitative factors may incorporate a prestige factor based on past accomplishments by an MBA program, not actually reflected in its current experience. Reputations reflect hard-won achievements, but also seem impervious to change from new challengers. In other words, reputation embodies "capital” that proves difficult to squander, once achieved. Moreover, the survey respondents' perception of the quantitative factors may reflect erroneous or incomplete information. In sum, the perceptions recorded in survey findings may significantly differ from the quantitative facts. ${ }^{3}$ This paper ranks MBA programs on numerous quantitative (“objective”) factors

\footnotetext{
${ }^{1}$ Since 2000, Business Week rankings include an intellectual-capital component, which incorporates the academic recognition of faculty members through journals articles and books. The student and recruiter surveys receive equal weight of 45 percent and the intellectual-capital component receives a weight of 10 percent.

${ }^{2}$ U.S. News \& World Report also reports business school rankings. But it includes both qualitative and quantitative factors in their overall index (ranking). Moreover, while it surveys corporate recruiters, it also employs survey information from business school deans and directors of accredited institutions, rather than a survey of former students, as Business Week does. Nonetheless, the final ranking includes the survey results - deans/directors and recruiters - with a 40-percent weight.

${ }^{3}$ Another issue, which we do not address, is the effects, if any, that the Business Week ranking may impose on resource allocation. Gioia and Corley (2002) argue that resources may flow from the enhancement of substance and
} 
and compares those rankings to the qualitative ("subjective”) rankings of the 2004 Business Week survey results.

The ranking of MBA programs may differ depending on the target audience. MBA students may value different criteria for ranking programs as compared to employers. Such variables as increase in salary from pre- to post-MBA program and the number of job offers post-MBA program reflect the interests of the MBA students. Employers, on the other hand, may value such factors as the selectivity of MBA programs, the GMAT scores of entering students, the faculty-student ratio, and the program's budget. That is, the value of the output from MBA programs largely represents the quality of inputs entering the MBA educational (production) process. Since the MBA programs must serve both the students and the employers, program administrators should value both sets of factors.

Conceptually, a professional education produces the stock of marketable human capital of the individuals graduating from the program. Although far from perfect, the salary offer received on graduation provides a reasonable index of the market value of the human capital. Students enter the MBA programs, however, with varying initial stocks of human capital. Pre-MBA earnings provide an index of the human capital acquired prior to entering the program. Thus, the incremental contribution of the program measures the differential between the pre- and post-MBA annual earnings, after adjusting for the cost of attending the MBA program. ${ }^{4}$ Most top-rated MBA programs admit only students with high GMAT scores. Thus, such programs pre-select their quality to public relations efforts to promote MBA-program image.

${ }^{4}$ For example, Stanford MBAs report median starting base salaries of $\$ 100,000$ and a total compensation package worth $\$ 150,000$ (including other compensation and a one time signing bonus) for the graduating class of 2004. For the graduates of Brigham Young University (BYU), the corresponding average base salary and total compensation package equal $\$ 70.500$ and $\$ 90,500$, respectively. It seldom gets mentioned that the average pre-MBA salary of Stanford's graduating classes already equals a high value of $\$ 80,000$ and a much more modest $\$ 31,000$ at BYU. In fact, when accounting for differences in tuition and other expenses, the annuitized value of the gain in earnings for BYU graduates exceeds that for the Stanford graduates, ranking second only to Michigan State University. 
graduates for a successful post-MBA career. In sum, the extent of "value added" gets overstated. But, as noted above, employers focus on the quality of new hires (output) and not the value added of the MBA program. Thus, employers flock to "prestigious" MBA programs because of the "perceived" high value of the inputs, which presumably produces high-value outputs (MBA graduates).

Gioia and Corley (2002) persuasively argue that since the advent of the Business Week and other ranking systems, business schools face the possible seduction into promoting image over substance. ${ }^{5}$ Their balanced approach to analyzing the effects of the Business Week rankings on the environment and culture of business schools identifies positive and negative implications. On the positive side, the Business Week and other rankings expose business schools to enhanced competition, increased the rate of adoption of innovations and new strategies, and improved transparency for more accountability. On the negative side, these subjective rankings fail to deliver on measuring educational quality, relying on subjective perceptions of students and corporate recruiters. Moreover, the ranking really compare MBA programs and not business schools. As such, undergraduate and $\mathrm{PhD}$ programs receive short shrift and the quality of faculty members only receives cursory attention. Finally, since the ratings partly reflect the opinion of one customer (students), faculty members face subtle and not-so-subtle pressure to lower the level and difficulty in course material, in effect pandering to customer demands.

A key component of the concerns raised by Gioia and Corley (2002) reflects the subjective nature of the survey of students and corporate recruiters. Our paper partly addresses these concerns

\footnotetext{
${ }^{5}$ Elsbach and Kramer (1996) examine how the Business Week rankings affect perceptions amongst business school faculty members. They conclude that "the rankings posed a two-pronged threat to many members' perceptions ... (1) calling into question their perception of highly valued, core identity attributes of their schools, and (2) challenging their beliefs about their school’s standing relative to other schools.” (p. 442).
} 
by proposing an objective methodology for ranking MBA programs. In this process, we also address the issue of arbitrary and un-normalized weights with our final indexes. That is, we use principal components analysis to develop indexes based on objective information. ${ }^{6}$

The next section reviews two different attempts to use quantitative data to rank MBA programs - a market-based, value-added approach, and a production-efficiency approach - and then previews our approach - a first-principal-component index of the quantitative information. Section 3 describes the data and its construction and then provides a descriptive analysis of the data used in our analysis. Section 4 constructs and interprets our alternative rankings based on the firstprincipal-component index. Section 5 concludes.

\section{Reputation and Ranking}

This section briefly reviews Tracy and Waldfogel (1997) and Ray and Jeon (2007), who each use quantitative data to rank MBA programs. Then, we preview our approach to developing a MBA program ranking based on an index of the objective data and subdividing the rankings into rankings that reflect the interests of students, employers, and program administrators.

Tracy and Waldfogel (1997) rank business schools employing what they call the "market-based" approach. Using regression analysis, they determine the value added by an MBA program, which they then use to rank MBA programs. ${ }^{7}$ Their ranking offers important information to MBA students, but it does not provide good, relevant information to employers

\footnotetext{
${ }^{6}$ We admit that the objective data only include self-reported information from the MBA programs themselves and provided to Business Week. Corley and Gioia (2000) report that one dean asserts that "Business schools lie!” (p. 326).

${ }^{7}$ They distinguish between the quality of an MBA program and the quality of its students. They regress the average starting salary (adjusted for differences in cost-of-living) on a number of student attributes and interpret the residual as value added by the program. Their revised ranking of MBA programs does contain a few surprises in that side by side with the heavyweights like Stanford, Harvard, and Chicago, much less recognized programs such as Oklahoma State, New Mexico, and Wake Forest feature in their "Value-Added Top 10" list.
} 
and only partial information for MBA program administrators. For example, a high-value-added program may start with lower quality students. Thus, employers may not find a high ranking that helpful. In other words, while value added may provide important information to MBA students, the total value may represent more valuable information to employers. Most importantly, as noted above, the quality of the inputs used in the production (educational) process determines total value, holding the MBA education value-added constant.

Decision making problems parallel production processes, where desirable outcomes of the decision play the role of outputs while actions or conditions facilitating these outcomes play the role of inputs. Good management education should produce efficient managers. Efficient management of production requires optimal utilization of resources. Efficiency proves inconsistent with either unrealized potential increase in output or avoidable waste of inputs. Ray and Jeon (2007) broaden the discussion of MBA program reputation or ranking to include production efficiency. Employing a production model and data envelopment analysis (DEA), they examine the reputation and production efficiency of MBA programs. ${ }^{8} 9$ The production process combines inputs to produce outputs. The calculation of a most efficient frontier then allows the computation of production efficiency for each of the MBA programs in the sample. They measure efficiency in three ways - output-oriented, input-oriented, and global efficiency measures. Output-oriented

\footnotetext{
${ }^{8}$ Charnes, Cooper, and Rhodes (1978) introduce the DEA method to non-parametrically measure technical efficiency of production units with reference to a technology exhibiting constant returns to scale. Subsequently, Banker, Charnes, and Cooper (1984) generalize the model to accommodate variable returns to scale.

${ }^{9}$ A number of studies use DEA to examine production and efficiency in education (e.g., Johnes and Johnes, 1993; Burton and Phimister, 1994; and Breu and Raab, 1994). Colbert, Levary and Shaner (2000) determine an alternative ranking of U.S. MBA programs based on DEA using the survey response scores reported in the Business Week study. They also compare the U.S. programs with three foreign MBA programs. As pointed out by Tracy and Waldfogel (1997), a valid ranking should incorporate quantitative criteria that are comparable across programs and should also be based on "outputs" rather than "inputs". The Colbert, Levary, and Shaner (2000) study, like the original Business Week ranking, falls short on this count.
} 
efficiency determines by how much one can technically increase output, using the observed inputs. Input-oriented efficiency determines by how much one can technically reduce inputs to produce the observed outputs. Finally, the global efficiency measure determines how much one can technically increase outputs and decrease inputs simultaneously to produce on the production frontier.

Similar to Tracy and Waldfogel (1997) and Ray and Jeon (2007), we also use quantitatively measured "inputs” and “outputs” rather than qualitative scores based on survey responses to rank the individual MBA programs. We explore the reputation or ranking of MBA programs using principal components analysis to generate indexes (i.e., the first principal component). Since the 2004 Business Week rankings only provide information for the top-30 MBA programs, we also compute simple averages of rankings based on the individual outputs and inputs used in the analysis. Thus, we can provide a ranking of MBA programs 31 to 65 to compare to our rankings based on principal components. ${ }^{10}$

Creating an index with which to rank MBA programs faces important conceptual issues. The use of multiple attributes (i.e., our outputs and inputs) in an index raises the issue of whether the measurement of these attributes, when aggregated into an overall index, gives undue influence to some attributes over others. Without normalizing the data series on attributes, attributes with larger averages or dispersions around the averages may exert extra influence on the final ranking. The Business Week ranking aggregates the raw survey data before ranking MBA programs. The description of the Business Week method states “...greater differences among the schools in the corporate survey, recruiter opinion tends to have a slightly greater weight in the overall ranking.” That is, because of a higher dispersion in the ranking by corporate

\footnotetext{
${ }^{10}$ The 2004 Business Week rankings include 68 MBA programs. Due to data problems with three schools, we analyze only 65 programs. See footnote 10 for more details.
} 
recruiters, their input receives more emphasis. In our rankings, we eliminate this possibility by normalizing all variables in the data set to the same mean and dispersion (i.e., standard deviation). ${ }^{11}$

Our simple, arithmetic ranking procedure uses equal weights on the numerical ranking of each attribute. That is, each MBA program receives a 1 to 65 ranking on each attribute. Thus, the mean (33) and standard deviation (18.9) do not change across attributes, which then receive equal weighting in the constructed indexes. Alternatively, principal component analysis begins by converting the attribute data into series with a zero mean and unit standard deviation and then forms the linear combination of the attributes that maximize the variance of the actual attribute data set explained. We employ the first principal component as the index for ranking purposes.

The use of quantitative (“objective”) information to rank programs brings forward an additional set of concerns. Much debate surrounds the U.S. News \& World Report college rankings (Ehrenberg 2005). First, rankings based, in whole or in part, on quantitative information induce institutional behavior that sometimes proves socially sub-optimal. In other words, to improve their quantitative numbers, institutions undertake perverse actions. For example, if a high yield rate (ratio of acceptances to offers) proves important, institutions may not make offers to highly qualified candidates who will likely choose another institution. Such actions by institutions make it more difficult for college-bound students to hedge their bets with some “safe” applications.

Second, aggregating quantitative information requires the use of weights with which to aggregate. Different individuals will exhibit different needs when choosing a college or business school, indicating a specific set of weights on the quantitative information. A one-size-fits-all

\footnotetext{
${ }^{11}$ U.S. News \& Worlds Report does normalize their data series before combining them into an overall index.
} 
approach does not work in practice. As such, this criticism suggests ranking programs across each piece of quantitative information and letting the user choose how to aggregate the disparate information. Regarding this second issue, Schatz (1993) criticizes the ranking of MBA programs using subjective surveys. He reports that the simple average of two quantitative factors - average GMAT scores and average starting salaries - replicates the Business Week and U.S. News \& World Report rankings.

How do we respond to these two concerns about quantitative information? At one level, we use the quantitative information to provide a comparison to the Business Week rankings, finding some significant adjustments in the rankings. At a more basic level, we provide the rankings across each piece of quantitative information as well as both a simple equal-weight and principal component aggregations of the quantitative information for students, employers, and MBA program administrators. Furthermore, many quantitative variables do not appear subject to the game playing behavior of business schools. For instance, the salary value added and GMAT scores do not seem subject to institutional corruption. The rejection rate, however, proves the exception. We offer more analysis of these issues when we describe the data. Finally, we also employ principal components analysis to let the data provide the different weight schemes when combining variables linearly that maximize the explained variability of the raw data.

\section{Data Definitions and Descriptive Analysis of MBA Programs}

In this study, we consider two outputs and six inputs contained in the business school production process. ${ }^{12}$ The first output (gain) measures the difference between the annuitized pre- and postMBA earnings flow of a representative graduate of the school, which we treat as the value added. Management education helps the students acquire and develop various management skills, which

\footnotetext{
12 The Appendix provides more details on data definitions and construction.
} 
make them more valuable to subsequent employers. Therefore, in an efficient market, a graduate with better skills relevant for effective management should receive a higher salary. The second output equals the adjusted placement rate (jobs). More worthy candidates usually generate multiple job offers. Given that the job placement rate does not reach 100 percent, however, we adjust the average number of offers received by the graduates who actually get any offer by the probability that a graduating student possesses an offer in hand.

The six inputs include: (i) the faculty-student ratio (f/s), (ii) the average GMAT score of the incoming class (gmat), (iii) the degree of selectivity in the admission process measured by the percentage of applications rejected (\%reject), (iv) the endowment per student (end/stud), (v) the percentage of male students in the class (\%male), and (vi) the percentage of U.S. students in the class (\%US). The faculty-student ratio measures an important school input. An increase in the faculty-student ratio should contribute positively to the output bundle. We measure the student's background in two alternative ways. One measure equals the percentage of applicants rejected for admission by a school. More selective the schools generate higher rejection rates and better quality graduating students. Self-selection, however, may occur in the applicant pools across MBA programs, where better applicants target only the more reputed MBA programs (e.g., Northwestern or Chicago). In that case, the second quartile of the pool of applicants for one school may include better applicants than the top quartile for another. Hence, an eighty-percent rejection rate for both MBA programs does not imply the same quality of admitted students. In sum, student self-selection adds noise to the information content of the rejection percentage. An alternative selectivity measure equals the average GMAT scores of the in-coming class. In this study, we include both measures of student quality as inputs. Finally, end/stud measures resources (endowment) per student.

When developing efficiency measures for the MBA programs, Ray and Jeon (2007) employ 
two additional input control variables for these two "qualitative dimensions" of the student input. Those two demographic variables, \%male and \%US, reflect characteristics of the students that may affect their salaries without affecting their managerial ability. Due to family constraints, a female MBA exhibits less mobility than the male MBA counterpart in her class, implying a lower female starting salary, on average. Also, a gender bias may exist against female graduates in the market. For both reasons, a school with a higher proportion of female students may experience a lower expected salary increase (pre- vs. post-MBA). Of course, entry-level differences in male and female salaries may mitigate this potential bias. Similar logic applies for a school with a higher proportion of international students. Due to visa problems, non-U.S.-resident MBAs often accept jobs with lower pay, on average. On the other hand, outstanding foreign-national MBAs may return to their own countries. As a result, the average salaries of those who accept employment in the U.S. are probably lower.

Table A1 in the appendix reports the input-output data for the individual MBA programs used in this study and the group-wise average values. We list the MBA programs based on their ranking in the 2004 Business Week (BW Rank) list. They group into 3 categories - tier-1 MBA programs consist of the top-30 programs, tier-2 MBA programs include the next 20 programs (unranked), and tier-3 MBA programs contain the last 15 programs (unranked). ${ }^{13}$ On average, the MBA programs in a higher category achieve higher salary gain and a better placement record than MBA programs from a lower category. At the individual school level, Michigan State shows the highest gain $(\$ 41,672)$, closely followed by Brigham Young University $(\$ 39,808)$. At the other end, Pepperdine shows a lowest gain of $\$ 7,295$. In terms of placement, Harvard with 2.4 job offers

\footnotetext{
${ }^{13}$ As noted in footnote 7, we did not obtain the information necessary to calculate the salary gain for three tier3 MBA programs - American, Northeastern, and Rutgers. We eliminate these three tier-3 programs in our analysis, dropping the tier-3 number from 18 to 15.
} 
per graduate proves most successful, while SUNY - Buffalo and the University of Connecticut with only 0.4 offers per graduate exhibit the poorest performance. Examining school resources, the top30 MBA programs possess a substantially lower faculty-student ratio and higher endowment per student than the programs in the other categories. For faculty-student ratios, Penn State exhibits the highest ratio (0.53) and Thunderbird the lowest (0.06). ${ }^{14}$ For endowments, Boston University, with an endowment per student of $\$ 1,108,894$ tops Harvard at $\$ 975,610$. Fordham’s endowment per student places dead last at \$995. MBA programs in higher categories exhibit, as expected, more selective classes with both higher average GMAT scores and higher rejection rates. Stanford accepts only 10 percent of the applicants and enrolls a class with an average GMAT score of 711, second highest in the sample. At the other extreme, Thunderbird with a rejection rate only 18 percent possesses an average GMAT score of only 587, third lowest in the sample. Based on the averages across the three tiers of MBA programs, the proportion of US students does not move much (between 66 and 70 percent) across all three categories. Florida International enrolls the largest proportion of foreign students (48 percent) and Brigham Young enrolls the smallest (14 percent). Similarly, the averages across the three tiers do not differ much in the percent female (between 70 and 73 percent). Fordham enrolls the largest proportion of female students (45 percent) and Florida International the smallest (4 percent).

\section{Constructing and Interpreting Alternative Rankings of MBA Programs}

As noted above, the Business Week rankings of MBA programs combine the raw survey results of students and employers (recruiters) to measure their combined perceptions of the quality of MBA programs. We argue that the combining of surveys, including students and employers, mixes apples

\footnotetext{
${ }^{14}$ As already noted, high-ranked MBA programs tend to exhibit low faculty-student ratios. For example, Chicago and Northwestern exhibit ratios of 0.07.
} 
and oranges. In this section, we develop several quantitative (“objective”) rankings of MBA programs that address the interests of students, employers, and MBA program administrators separately. ${ }^{15}$ Moreover, we compare those quantitative rankings with the qualitative (“subjective”) Business Week rankings.

First, consider the interests of the students, which, we argue, reflect the value added (gain) and the adjusted number of job offers (jobs) produced by MBA programs, which capture our output measures. We ranked the MBA programs based on value added and job offers separately. Then we took arithmetic averages of the rankings on these two dimensions and ranked the resulting outcomes to generate an overall output ranking (Output). Further, we applied principal components analysis to gain and jobs and used the weights of the first principal component to construct another overall output index to rank programs (Output-pc). Table 1 reports the findings. ${ }^{16}$ Columns 7 and 8 in Table 1 report the differences between the arithmetic average (Output) and principal component (Output-pc) rankings (Difference) and also those of the Business Week (BW Rank) and principal component (Output-pc) rankings (Difference-pc). ${ }^{17}$

The evidence presented in Table 1 elicit several observations. Several high-ranking MBA programs in the Business Week survey rank far down the list based on value added (gain). When we consider the top-10 programs in the Business Week ranking, Chicago, Stanford, Harvard, Michigan, and Columbia each rank in the top-10 Business Week ranking, but fall below a rank of

\footnotetext{
${ }^{15}$ Colbert, Levary, and Shaner (2000) also separate student and employer (recruiter) satisfaction in their analysis. They do not explicitly associate the combined satisfaction measure with the interests of MBA program administrators.

${ }^{16}$ The first principal component for the output index produces weights on the normalized value added and adjusted jobs per student variables that equal 0.7071 and 0.7071 , respectively. In sum, equal weights apply to value added and adjusted jobs per student. The notes to Tables 1 to 3 also report Spearman rank correlations between our various rankings.

${ }^{17}$ Since Business Week only ranks the top-30 MBA programs, Difference-pc only exists for the top-30 programs.
} 
$50^{\text {th }}$ using the objective value added (gain) measure. Only Pennsylvania remains in the top-10, using value added. The nine new entrants to the top-10 list come from a wide range of schools, beginning with Virginia that moves from $12^{\text {th }}$ to $4^{\text {th }}$ down to Arizona that jumps from the unranked Tier-3 list of MBA programs from $51^{\text {st }}$ to $5^{\text {th }}$.

The ranking based on the number of adjusted job offers per student (jobs) does not exhibit such dramatic changes from the original Business Week ranking. ${ }^{18}$ Now, eight of the top-10 MBA programs remain in the top-10 programs ranked by adjusted number of jobs per student. Only Cornell and Dartmouth fall out of the top-10, landing at $27^{\text {th }}$ and $11^{\text {th }}$, respectively. Washington Seattle and Syracuse, tier-2 and tier-3 MBA programs, respectively, enter the top-10 based on the ranking by the adjusted number of jobs per student. In other words, the adjusted number of jobs per student provides a closer connection to the Business Week rankings than does the value added.

Our two overall rankings based on the two outputs - the arithmetic average and the principal components index - both allow a ranking of the MBA programs outside the top-30 (i.e., the tier-2 and tier-3 MBA programs). The Spearman rank correlation coefficient between the arithmetic average ranking (Output) and the value added and adjusted jobs per student variables equal 0.77 and 0.73 , respectively. The Spearman rank correlation coefficient between the principal components ranking (Output-pc) and the value added and adjusted jobs per student equal 0.58 and 0.75 , respectively. Note that the Spearman rank correlation coefficient rises when considering the principal component index and moving from value added to adjusted jobs per student, which is consistent with our earlier observation about the relative correspondence of these two output measures with the original Business Week ranking. In other words, the principal components index possesses a closer correlation with adjusted jobs per student than with value added.

\footnotetext{
${ }^{18}$ See the appendix for the adjustment of the number of job offers per student.
} 
Consider, next, the top-30 MBA programs in the Business Week ranking. Several programs experience significant decreases in their ranking based on the arithmetic average and principal component index rankings. ${ }^{19}$ For example, Chicago, Stanford, Michigan, Cornell, Texas - Austin, Babson, and Southern California fall by more than 20 places in the rankings based on the principal component ranking. Other top-30 MBA programs rise in the rankings with Rochester, Georgetown, and Purdue increasing by more than 10 places each. Some MBA programs jump from the tier-2 and tier-3 categories to the top-10, suggesting that potential students should give these programs special attention, especially if value added and adjusted job offers per student prove important in their individual decision making process. Brigham Young, Minnesota, Washington - Seattle, and Syracuse all jump into the top-10 programs based on our output based principal component ranking. Other programs - Boston University, Ohio State, Penn State, Wake Forest, and Arizona also deserve note by jumping into the second-10 programs.

Second, consider the interests of the employer, which reflect the faculty-student ratio $(f / s)$, the rejection percentage (\%reject), the GMAT score (gmat), and the endowment per student (end/stud) invested by the MBA program into the pool of students attracted to the MBA program, given their screening devices. As we did for our output measures, we rank MBA programs based on each individual input. Next, we compute the simple average of those numerical input rankings and the first principal component of those inputs to generate an overall input (Input) and principal component (Input-pc) rankings. ${ }^{20}$ Then, we compare our quantitative (“objective”) rankings with

\footnotetext{
${ }^{19}$ The Spearman rank correlation coefficient between the arithmetic average and the principal component rankings equals 0.90 . We will discuss in the text only the results based on the principal component ranking, leaving any analysis of the arithmetic average ranking to the reader.

${ }^{20}$ The first principal component for the four inputs produces weights on the normalized faculty-student ratio, the GMAT score, the rejection percentage, and the endowment per student variables that equal $-0.3683,0.6348,0.5847$, and 0.3456, respectively. In sum, the highest weights go to the GMAT score and the rejection rate, whereas the faculty student ratio and endowment per student receive smaller weights.
} 
each other and then to the qualitative (“subjective”) rankings from the Business Week survey. Table 2 reports the findings with columns 9 and 10 on the differences between our overall input (Input) and the principal component (Input-pc) rankings and between the Business Week (BW Ranking) rankings and our principal component (Input-pc) ranking.

The rankings of MBA programs based on individual inputs generate some interesting observations. Higher rejection percentages or higher GMAT scores associate with a higher Business Week ranking. That is, higher ranked MBA programs prove much more selective in admitting students into their programs, not a surprise. Also, higher endowment per student associates with a higher Business Week ranking. Unexpectedly, a lower faculty-student ratio associates with a higher Business Week ranking. We interpret this observation as follows. Higher ranked MBA programs in Business Week select students with high ability and promise. Moreover, a low faculty-student ratio implies, on average, a large MBA program. Thus, employers can pick from a large pool of extremely promising students. Conversely, a large faculty-student ratio may signal a small MBA program with many fewer students in any graduating class. ${ }^{21}$

Unlike our findings for objective output measures, where the ranking based on value added (gain) does not closely correspond to the Business Week ranking, the individual objective input variables produce rankings that uniformly exhibit a closer connection to the Business Week subjective rankings. Among the four input measures, however, the GMA score and the rejection rates possess a closer connection to the Business Week rankings. For example, 5, 4, 2, and 6 MBA programs drop out of the top-10 Business Week rankings when using the faculty student ratio, the

\footnotetext{
${ }^{21}$ Viewed another way, high-reputation MBA programs usually enroll more students, run larger classes, and use a lower faculty-student ratio. Examining the raw Business Week data on faculty and students, higher ranked MBA programs often employ and enroll more faculty and students, respectively, although the enrollment of students rises more rapidly than employment of faculty so that the faculty student ratio falls.
} 
GMAT score, the rejection rate, and the endowment per student to rank programs, respectively. Further, the number dropping out of the top-20 programs equal 7, 3, 6, and $11 .^{22}$

The rankings based on the principal component index of inputs generate the following observations. ${ }^{23}$ Only two MBA programs - Michigan and Cornell - drop out of the top-10 Business Week ranking, getting replaced by Berkeley and Yale, rising from $17^{\text {th }}$ and $22^{\text {nd }}$, respectively. Further, three programs - North Carolina, Indiana, and Texas, Austin - drop out of the top-20, getting replaced by Yale, Southern California, and Boston University. Southern California ranked $27^{\text {th }}$ in the Business Week survey whereas Boston University appeared in the unranked tier-2.

Consider the top-30 MBA program in the Business Week survey. Several programs experience significant downgrading in their ranking, using the principal component index of inputs (Input-pc). Cornell in the top-10 drops by 10 places to $17^{\text {th }}$. In addition, North Carolina and Indiana in the second 10 drop by 20 and 19 places, ending up at $36^{\text {th }}$ and $37^{\text {th }}$, respectively. Moreover, Babson and Vanderbilt in the third 10 drop by 25 and 20 places, ending up at $51^{\text {st }}$ and $50^{\text {th }}$, respectively. Other top-30 programs in the Business Week rankings advance based on ranking by the principal component index of inputs. Harvard jumps four places from $5^{\text {th }}$ to $1^{\text {st }}$. MIT leapfrogs 6 places from $9^{\text {th }}$ to $3^{\text {rd }}$. In addition, Yale hurdles ahead by 18 places from $22^{\text {nd }}$ to $4^{\text {th }}$.

Using the principal components index of inputs to rank MBA programs produces fewer programs jumping from tier-2 or tier-3 to the top 30 than occurs for the principal component index of outputs (see above). Among tier-2 program, Boston University does the best, moving to $19^{\text {th }}$,

\footnotetext{
${ }^{22}$ The Spearman rank correlation coefficients between the rankings based on the first principal component index of inputs and the rankings based on the individual inputs faculty student ratio, the GMAT score, the rejection rate, and the endowment per student equal $0.54,0.84,0.75$. and 0.38 , respectively. Also, see footnote 16 where the principal component weights reflect a similar pattern.

${ }^{23}$ Once again, we focus on the rankings based on the principal component index. The Spearman rank correlation coefficient between the rankings based on the arithmetic average of inputs and the principal component index equals 0.86 .
} 
while among tier-3 programs, Florida does the best, moving to $23^{\text {rd }}$.

Third, we consider the interests of MBA program administrators, which, we argue, reflect the interests of the students and employers. That is, program administrators consider both outputs and inputs. We take the objective output and input rankings for individual components developed respectively in Tables 1 and 2, calculate an arithmetic average across all output and input rankings as well as the first principal component of the outputs and inputs together, producing the combined (Combined) and the principal component (Combined-pc) rankings. ${ }^{24}$ Since the Business Week method uses surveys of students and employees, that ranking comes the closest, in spirit to our combined and principal component rankings. The crucial difference, however, remains - our rankings use quantitative (“objective”) data while the Business Week survey incorporates qualitative ("subjective”) judgment. Columns 7 and 8 in Table 3 report the differences between our combined (Combined) and principal component (Combined-pc) rankings, and those between the Business Week (BW Ranking) and our principal component (Combined-pc) ranking.

The rankings of MBA programs based on arithmetic averages of outputs (Output) and inputs (Inputs) reflect the rankings reported for outputs and inputs in Tables 1 and 2, respectively. We report these rankings in Table 3 for ease of comparison with the new rankings in Table 3 . The rankings based on the principal component index of outputs and inputs (Combined-pc) generally come closer to the findings for the rankings based on the principal component index of inputs (Input-pc). ${ }^{25}$ Only two MBA programs - Michigan and Cornell - drop out of the top-10 Business

\footnotetext{
${ }^{24}$ The first principal component for the two outputs and four inputs produces weights on the value added, adjusted jobs per student, normalized faculty-student ratio, the GMAT score, the rejection percentage, and the endowment per student variables that equal $0.1201,0.4988,-0.2928,0.5431,0.5117$, and 0.3071 , respectively. In sum, the adjusted jobs per student, the GMAT scores, and the rejection rate receive similar weighting in the index, whereas the other three variables receive smaller and similar weights with value added the lowest weight. In sum, adjusted jobs per student, the GMAT score, and the rejection rate provide the most information in the principal components index.

${ }^{25}$ Once again, we focus on the rankings based on the principal component index. The Spearman rank correlation
} 
Week ranking, getting replaced by Berkeley and Yale, rising from $17^{\text {th }}$ and $22^{\text {nd }}$, respectively. Further, three programs - North Carolina, Indiana, and Texas, Austin - drop out of the top-20, getting replaced by Yale, Rochester, and Washington, Seattle. Rochester ranked $29^{\text {th }}$ in the Business Week survey whereas Washington, Seattle appeared in the unranked tier-2.

Consider the top-30 MBA program in the Business Week survey. Several programs experience significant downgrading in their ranking, using the principal component index of outputs and inputs (Combined-pc). Cornell in the top-10 drops by 11 places to $18^{\text {th }}$, whereas Chicago and Michigan each drop 7 places to $9^{\text {th }}$ and $13^{\text {th }}$, respectively. In addition, North Carolina and Indiana in the second 10 drop by 21 and 14 places, ending up at $37^{\text {th }}$ and $32^{\text {nd }}$, respectively. Moreover, Babson and Vanderbilt in the third 10 drop by 28 and 19 places, ending up at $54^{\text {th }}$ and $49^{\text {th }}$, respectively. Other top-30 programs in the Business Week rankings advance based on ranking by the principal component index of outputs and inputs. Harvard jumps four places from $5^{\text {th }}$ to $1^{\text {st }}$. MIT leapfrogs 6 places from $9^{\text {th }}$ to $3^{\text {rd }}$. In addition, Yale hurdles ahead by 14 places from $22^{\text {nd }}$ to $8^{\text {th }}$ and Rochester bounds ahead by 10 places from $29^{\text {th }}$ to $19^{\text {th }}$.

Using the principal components index of outputs and inputs to rank MBA programs produces fewer programs jumping from tier-2 or tier-3 to the top 30 than occurs for the principal component index of outputs (see above). Among tier-2 program, Washington, Seattle does the best, moving to $17^{\text {th }}$, followed closely by Boston University and Ohio State, moving to $21^{\text {st }}$ and $22^{\text {nd }}$, respectively, while among tier-3 programs, Florida does the best, moving to $28^{\text {th }}$.

How do the top-10 MBA programs in the Business Week ranking fare across our multiple ranking schemes? Only two MBA programs - Pennsylvania and MIT - remain in the top-10 across

coefficient between the rankings based on the arithmetic average of outputs and inputs and the principal component index equals 0.92 . 
our 6 cumulative rankings - that is, Output and Output-pc (Table 1), Input and Input-pc (Table 2), and Combined and Combined-pc (Table 3) rankings. That outcome entirely reflects the fact that only these two top-10 Business Week programs remain in our top-10 Output and Output-pc rankings. ${ }^{26}$ Excluding our Output and Output-pc rankings, 7 MBA programs all remain in the top10 programs in our other 4 ranking schemes. Only Chicago, Michigan, and Cornell fail to achieve a top-10 ranking in all four remaining rankings. Expanding our view to the top-30 Business Week MBA programs and, once again, considering all 6 cumulative rankings, 13 programs Northwestern, Pennsylvania, Harvard, Columbia, MIT, Dartmouth, Duke, Virginia, NYU, Carnegie Mellon, Berkeley, Yale, and Rochester - also appear in each of our top-30 cumulative rankings. Excluding the Output and Output-pc rankings, 7 additional programs - Chicago, Stanford, Michigan, Cornell, UCLA, Texas, Austin, and Emory - do not drop out of the top-30.

\section{Conclusion}

The ranking of MBA programs by Business Week provides important information for employers, students, and program administrators. That ranking, however, mixes the responses of students and employers together, giving an overall evaluation of the MBA programs. Students, employers, and program administrators, we argue, potentially possess different interests that should reflect different characteristics in their individual ranking schemes. This paper provides different ranking schemes for these three different groups.

The Business Week ranking relies on the perceptions of the participants in its MBA program survey. That is, survey respondents will use both quantitative and qualitative factors in responding to the survey. Moreover, the survey respondents may not possess accurate information

\footnotetext{
${ }^{26}$ Our Output and Output-pc rankings reflect the interests of students, and not the interests of employers or program administrators.
} 
on the quantitative facts. The qualitative factors critically include the reputation of the program receiving a ranking. Reputations take much time and effort to build. But once established, they can persist for a long time, even if the effort to maintain the program slackens after establishing its reputation. Thus, MBA programs attempting to climb in the rankings will feel that the survey does not adequately reward the efforts that they have made to improve their program. In addition, MBA programs with strong reputations may continue to rank highly, even after the quality of the program deteriorates. This paper provides rankings based on quantitative (“objective”) factors and compares those rankings to the Business Week rankings that incorporate qualitative (“subjective”) factors.

The various rankings divide into three groups as follows. Student rankings reflect two outputs - the gain in income from pre- to post-MBA program adjusted for the cost of attending the program and the average number of job offers received. Employer rankings reflect four inputs -the faculty student ratio, the average GMAT score, the rejection percentage, and endowment per student for the programs. ${ }^{27}$ Finally, the MBA program administrator rankings reflect both the outputs and the inputs. We employ two approaches to combining information to achieve an overall ranking - arithmetic averages of the ranking numbers for each of the variables used in the overall ranking and the first principal component drawn from those same variables.

Our two ranking methods both solve a problem that the Business Week rankings do not properly address. To wit, Business Week combines the raw data from the student and corporate recruiter surveys without normalizing the series. As Business Week reports, the corporate recruiter surveys garner more influence in the final ranking, since corporate recruiters exhibit a larger dispersion in ranking MBA programs relative to students. Our unweighted average of the numerical rankings and the weighted first principal component index both normalize the data

\footnotetext{
${ }^{27}$ Note that student self-selection adds some noise to the information content of the rejection percentage.
} 
series, albeit in different ways, so that each attribute possesses the same mean and standard deviation. Thus, in our method, no one attribute achieves undue influence on the final rankings. ${ }^{28}$

Considering the two output and four input variables, we find that the value added construct provides the least information consistent with the original Business Week ranking. That is, many highly ranked MBA programs do not deliver the value added as some much lesser ranked programs. To the extent that value added becomes an important criteria in a student's decision as to which program to attend, the Business Week ranking proves less than helpful. On this one criteria, some specific tier-2 and tier-3 MBA programs such as Brigham Young, Michigan State, and Arizona deserve careful consideration by students. ${ }^{29}$

In sum, some MBA programs rise and others fall dramatically in the quantitative (“objective”) rankings as compared to the Business Week rankings. Moreover, we observe differences in the reshufflings of the rankings of MBA programs based on whether the focus reflects student, employer, or program administrator interests.

\footnotetext{
${ }^{28}$ The principal component method uses the characteristics of the data series to determine weights in the final index, allowing for different variables to exert more or less influence on the overall ranking index. See discussions in the text.

${ }^{29}$ These programs, however, report the $2^{\text {nd }}$ (Arizona), $3^{\text {rd }}$ (Brigham Young), and $8^{\text {th }}$ (Michigan State) lowest preMBA salaries of all the programs in the sample. That is, students with high pre-MBA salaries may not achieve the value added at these schools, since they enter the high end of the pre-MBA salary distribution. In other words, if a student possesses a high pre-MBA salary, then choosing an MBA program based on value added may prove problematic. Such high pre-MBA-salary students may not want to pursue an MBA degree unless they matriculate at a high-ranking MBA program in the Business Week survey.
} 


\section{References:}

Banker, R. D., A. Charnes, and W. W. Cooper (1984). "Some Models for Estimating Technical and Scale Inefficiencies in Data Envelopment Analysis.” Management Science, pp 1078-1092.

Breu, T. M., and R. L. Raab, (1994). "Efficiency and Perceived Quality of the Nation's "Top 25" National Universities and national Liberal Arts Colleges: An Application of Data Envelopment Analysis to Higher Education." Socio-Economic Planning Sciences, vol. 28, pp 33-45.

Burton, M. P. and E. Phimister, (1995). "Core Journals: A Reappraisal of the Diamond List." The Economic Journal, vol. 105, pp 361-373.

Charnes, A., W. W. Cooper, and E. Rhodes, (1978). "Measuring the Efficiency of Decision Making Units." European Journal of Operational Research, vol. 2, pp 429-444.

Colbert, A., R. A. Levary, and M. C. Shaner, (2000). "Determining the Relative Efficiency of MBA Programs using DEA.” European Journal of Operational Research, vol. 125, pp 656-669.

Corley, K. G., and D. A. Gioia, (2000). “The Rankings Game: Managing Business School Reputation.” Corporate Reputation Review, vol. 3, pp. 319-333.

Ehrenberg, R. G., (2005). "Method or Madness? Inside the USNWR College Rankings.” Journal of College Admissions, forthcoming.

Elsbach, K. D., and R. M. Kramer, (1996). "Members' Responses to Organizational Identity Threats: Encountering and Countering Business Week Rankings.” Administrative Science Quarterly, vol. 41, pp. 442-476.

Gioia, D. A., and K. G. Corley, (2002). "Being Good Versus Looking Good: Business School Rankings and the Circean Transformation from Substance to Image." Academy of Management Learning and Education, vol. 1, pp. 107-120.

Jeon, Y., S. M. Miller, and S. C. Ray, (2003). "MBA Program Reputation: Objective Rankings for Students, Employers, and Program Administrators.” University of Connecticut Working Paper \#2003-28, available at http://www.econ.uconn.edu/working/2003-28.pdf.

Johnes, G. and J. Johnes, (1993). "Measuring the Research Performance of U.K. Economics Departments: An Application of Data Envelopment Analysis." Oxford Economic Papers, vol. 45, pp 332-347.

Ray, S. C. and Y. Jeon, (2007). "Reputation And Efficiency: A Nonparametric Assessment of America's Top-Rated MBA Programs.” European Journal of Operations Research, in press. 
Schatz, M., (1993). "What’s Wrong with MBA Ranking Surveys?” Management Research Notes, vol. 16, pp. 15-18.

Tracy, J. and J. Waldfogel, (1997). "The Best Business Schools: A Market-Based Approach.” Journal of Business, vol. 70(1), 1-31. 
Table 1: Business Schools Ranked by Outputs

\begin{tabular}{|c|c|c|c|c|c|c|c|}
\hline $\begin{array}{c}\text { BW } \\
\text { Rank }\end{array}$ & School Name & gain & jobs & Output & Output-pc & Difference & Difference-pc \\
\hline 1 & Northwestern (Kellog) & 36 & 7 & 17 & 10 & 7 & -9 \\
\hline 2 & Chicago & 55 & 9 & 34.5 & 27 & 7.5 & -25 \\
\hline 3 & Pennsylvania (Wharton) & 8 & 4 & 1 & 1 & 0 & 2 \\
\hline 4 & Stanford & 61 & 5 & 39.5 & 32 & 7.5 & -28 \\
\hline 5 & Harvard & 56 & 1 & 27 & 3 & 24 & 2 \\
\hline 6 & Michigan (Ross) & 51 & 10 & 32 & 30 & 2 & -24 \\
\hline 7 & Cornell (Johnson) & 39 & 27 & 39.5 & 39 & 0.5 & -32 \\
\hline 8 & Columbia & 52 & 8 & 30.5 & 25 & 5.5 & -17 \\
\hline 9 & MIT (Sloan) & 14 & 2 & 2 & 2 & 0 & 7 \\
\hline 10 & Dartmouth (Tuck) & 35 & 11 & 21 & 19 & 2 & -9 \\
\hline 11 & Duke (Fuqua) & 15 & 20 & 9 & 11 & -2 & 0 \\
\hline 12 & Virginia (Darden) & 4 & 28 & 5.5 & 14 & -8.5 & -2 \\
\hline 13 & NYU (Stern) & 42 & 13 & 25 & 28 & -3 & -15 \\
\hline 14 & UCLA (Anderson) & 48 & 12 & 30.5 & 33 & -2.5 & -19 \\
\hline 15 & Carnegie Mellon (Tepper) & 21 & 25 & 21 & 23 & -2 & -8 \\
\hline 16 & UNC (Kenan-Flager) & 9 & 42 & 24 & 26 & -2 & -10 \\
\hline 17 & UC Berkeley (Haas) & 26 & 16 & 16 & 18 & -2 & -1 \\
\hline 18 & Indiana (Kelley) & 3 & 33 & 10.5 & 15 & -4.5 & 3 \\
\hline 19 & Texas - Austin (McCombs) & 32 & 40 & 43.5 & 44 & -0.5 & -25 \\
\hline 20 & Emory (Goizueta) & 41 & 22 & 33 & 36 & -3 & -16 \\
\hline 21 & Purdue (Krannert) & 19 & 14 & 7.5 & 8 & -0.5 & 13 \\
\hline 22 & Yale & 18 & 26 & 18.5 & 21 & -2.5 & 1 \\
\hline 23 & Washington (Olin) & 13 & 31 & 18.5 & 24 & -5.5 & -1 \\
\hline 24 & Notre Dame (Mendoza) & 6 & 43 & 23 & 22 & 1 & 2 \\
\hline 25 & Georgetown (McDonough) & 12 & 21 & 7.5 & 13 & -5.5 & 12 \\
\hline 26 & Babson (Olin) & 57 & 55 & 60.5 & 57 & 3.5 & -31 \\
\hline 27 & Southern California (Marshall) & 60 & 52 & 60.5 & 61 & -0.5 & -34 \\
\hline 28 & Maryland (Smith) & 29 & 39 & 42 & 43 & -1 & -15 \\
\hline 29 & Rochester (Simon) & 7 & 24 & 4 & 9 & -5 & 20 \\
\hline 30 & Vanderbilt (Owen) & 27 & 38 & 37 & 40 & -3 & -10 \\
\hline 31 & Arizona State (Cary) & 34 & 45 & 45 & 45 & 0 & na \\
\hline 31 & Boston College (Carroll) & 31 & 57 & 48.5 & 49 & -0.5 & na \\
\hline 31 & Boston University & 16 & 49 & 37 & 37 & 0 & na \\
\hline 31 & Brigham Young (Marriott) & 2 & 30 & 5.5 & 6 & -0.5 & na \\
\hline 31 & Case Western (Weatherhead) & 30 & 37 & 41 & 60 & -19 & na \\
\hline 31 & Georgia (Terry) & 64 & 60 & 64 & 42 & 22 & na \\
\hline 31 & Georgia Tech (DuPree) & 46 & 46 & 50 & 64 & -14 & na \\
\hline 31 & Illinois -- Urbana-Champaign & 58 & 50 & 58 & 48 & 10 & na \\
\hline 31 & Iowa (Tippie) & 33 & 32 & 37 & 56 & -19 & na \\
\hline 31 & Michigan State (Broad) & 1 & 35 & 10.5 & 38 & -27.5 & na \\
\hline 31 & Minnesota (Caarlson) & 23 & 15 & 12 & 4 & 8 & na \\
\hline 31 & Ohio State (Fisher) & 10 & 29 & 13 & 12 & 1 & na \\
\hline 31 & Penn State (Smeal) & 20 & 44 & 34.5 & 20 & 14.5 & na \\
\hline 31 & Rice (Jones) & 47 & 54 & 55 & 35 & 20 & na \\
\hline
\end{tabular}


Table 1: Business Schools Ranked by Outputs (continued)

\begin{tabular}{|c|l|c|c|c|c|c|c|}
\hline $\begin{array}{c}\text { BW } \\
\text { Rank }\end{array}$ & \multicolumn{1}{|c|}{ School Name } & gain & jobs & Output & Output-pc & Difference & Difference-pc \\
\hline $\mathbf{3 1}$ & Southern Methodist (Cox) & 28 & 53 & 46 & 53 & -7 & na \\
\hline $\mathbf{3 1}$ & Thunderbird & 49 & 62 & 59 & 46 & 13 & na \\
\hline $\mathbf{3 1}$ & UC Irvine (Merage) & 62 & 41 & 57 & 59 & -2 & na \\
\hline $\mathbf{3 1}$ & Wake Forest (Babcock) & 17 & 23 & 14 & 16 & -2 & na \\
\hline $\mathbf{3 1}$ & Washington - Seattle & 22 & 6 & 3 & 5 & -2 & na \\
\hline $\mathbf{3 1}$ & Wisconsin - Madison & 11 & 47 & 29 & 34 & -5 & na \\
\hline $\mathbf{5 1}$ & Arizona (Eller) & 5 & 36 & 15 & 17 & -2 & na \\
\hline $\mathbf{5 1}$ & SUNY - Buffalo & 24 & 64 & 48.5 & 52 & -3.5 & na \\
\hline $\mathbf{5 1}$ & Connecticut & 37 & 65 & 56 & 58 & -2 & na \\
\hline $\mathbf{5 1}$ & Florida (Warrington) & 59 & 34 & 51 & 55 & -4 & na \\
\hline $\mathbf{5 1}$ & Florida International & 63 & 59 & 63 & 63 & 0 & na \\
\hline $\mathbf{5 1}$ & Fordham & 44 & 56 & 54 & 54 & 0 & na \\
\hline $\mathbf{5 1}$ & George Washington & 54 & 18 & 43.5 & 41 & 2.5 & na \\
\hline $\mathbf{5 1}$ & Pepperdine (Seaver) & 65 & 63 & 65 & 65 & 0 & na \\
\hline $\mathbf{5 1}$ & Pittsburgh (Katz) & 38 & 19 & 27 & 29 & -2 & na \\
\hline $\mathbf{5 1}$ & South Carolina (Darla Moore) & 53 & 61 & 62 & 62 & 0 & na \\
\hline $\mathbf{5 1}$ & Syracuse (Whitman) & 43 & 3 & 21 & 7 & 14 & na \\
\hline $\mathbf{5 1}$ & Tennessee - Knoxville & 50 & 48 & 53 & 50 & 3 & na \\
\hline $\mathbf{5 1}$ & Texas A\&M (Mays) & 40 & 17 & 27 & 31 & -4 & na \\
\hline $\mathbf{5 1}$ & Tulane (Freeman) & 25 & 58 & 47 & 47 & 0 & 1 \\
\hline $\mathbf{5 1}$ & William and Mary (Mason) & 45 & 51 & 52 & 51 & & na \\
\hline
\end{tabular}

Note: $\quad B W$ Rank means the original Business Week ranking. The Output column comes by an arithmetic unweighted average of the gain and jobs columns with a ranking of the resulting average numbers from 1 to 65. The Output-pc column provides the ranking based on the weighted first principal component of the gains and jobs variables with both weights on the normalized values equal to 0.70711. The Difference column measures the difference between the Output ranking (column 5) and the Output-pc ranking (column 6). The Difference-pc column measures the difference between the Business Week ranking (column 1) and the Output$p c$ ranking (column 6), which only applies to the 30 programs actually ranked individually in the Business Week ranking. Thus, in the difference columns 7 and 8, a positive number means an improvement in ranking relative to the Output and Business Week rankings, respectively. For example, Rochester improves 20 positions from the Business Week to the Outputs-pc rankings, but falls by 5 positions from the Output to the Output-pc rankings. Spearman rank correlations between the Output-pc ranking and our value added (gains), job offers (jobs), and overall output (Output) rankings equals $0.58,0.75$, and 0.90 , respectively. 
Table 2: Business Schools Ranked by Inputs

\begin{tabular}{|c|c|c|c|c|c|c|c|c|c|}
\hline $\begin{array}{c}\text { BW } \\
\text { Rank }\end{array}$ & School Name & $\mathrm{f} / \mathrm{s}$ & gmat & \%reject & end/stud & Input & Input-pc & Difference & Difference-pc \\
\hline 1 & Northwestern (Kellog) & 3 & 9 & 10 & 15 & 4.5 & 8 & -3.5 & -7 \\
\hline 2 & Chicago & 2 & 13 & 9 & 43 & 11.5 & 10 & 1.5 & -8 \\
\hline 3 & Pennsylvania (Wharton) & 20 & 1 & 4 & 13 & 6 & 5 & 1 & -2 \\
\hline 4 & Stanford & 23 & 2 & 1 & 3 & 2 & 2 & 0 & 2 \\
\hline 5 & Harvard & 9 & 4 & 2 & 2 & 1 & 1 & 0 & 4 \\
\hline 6 & Michigan (Ross) & 4 & 14 & 19 & 28 & 9 & 14 & -5 & -8 \\
\hline 7 & Cornell (Johnson) & 12 & 20 & 21 & 16 & 13 & 17 & -4 & -10 \\
\hline 8 & Columbia & 7 & 5 & 3 & 19 & 3 & 7 & -4 & 1 \\
\hline 9 & MIT (Sloan) & 18 & 11 & 7 & 5 & 7 & 3 & 4 & 6 \\
\hline 10 & Dartmouth (Tuck) & 14 & 7 & 6 & 10 & 4.5 & 6 & -1.5 & 4 \\
\hline 11 & Duke (Fuqua) & 6 & 3 & 24 & 39 & 14 & 13 & 1 & -2 \\
\hline 12 & Virginia (Darden) & 13 & 18 & 29 & 7 & 11.5 & 15 & -3.5 & -3 \\
\hline 13 & NYU (Stern) & 29 & 10 & 8 & 49 & 17 & 12 & 5 & 1 \\
\hline 14 & UCLA (Anderson) & 5 & 6 & 11 & 52 & 15 & 11 & 4 & 3 \\
\hline 15 & Carnegie Mellon (Tepper) & 38 & 15 & 13 & 63 & 25 & 16 & 9 & -1 \\
\hline 16 & UNC (Kenan-Flager) & 34 & 37 & 44 & 38 & 39 & 36 & 3 & -20 \\
\hline 17 & UC Berkeley (Haas) & 24 & 8 & 5 & 29 & 10 & 9 & 1 & 8 \\
\hline 18 & Indiana (Kelley) & 49 & 43 & 17 & 50 & 43 & 37 & 6 & -19 \\
\hline 19 & Texas - Austin (McCombs) & 16 & 21 & 35 & 31 & 18 & 22 & -4 & -3 \\
\hline 20 & Emory (Goizueta) & 36 & 17 & 25 & 32 & 20 & 20 & 0 & 0 \\
\hline 21 & Purdue (Krannert) & 48 & 22 & 38 & 42 & 37.5 & 34 & 3.5 & -13 \\
\hline 22 & Yale & 22 & 12 & 12 & 4 & 8 & 4 & 4 & 18 \\
\hline 23 & Washington (Olin) & 15 & 41 & 53 & 11 & 24 & 31 & -7 & -8 \\
\hline 24 & Notre Dame (Mendoza) & 55 & 31 & 46 & 8 & 30 & 35 & -5 & -11 \\
\hline 25 & Georgetown (McDonough) & 44 & 27 & 34 & 55 & 44 & 33 & 11 & -8 \\
\hline 26 & Babson (Olin) & 35 & 50 & 54 & 18 & 42 & 51 & -9 & -25 \\
\hline 27 & Southern California (Marshall) & 25 & 16 & 23 & 41 & 19 & 18 & 1 & 9 \\
\hline 28 & Maryland (Smith) & 39 & 38 & 28 & 56 & 45.5 & 32 & 13.5 & -4 \\
\hline 29 & Rochester (Simon) & 17 & 25 & 26 & 24 & 16 & 21 & -5 & 8 \\
\hline 30 & Vanderbilt (Owen) & 21 & 56 & 61 & 9 & 35 & 50 & -15 & -20 \\
\hline 31 & Arizona State (Cary) & 61 & 39 & 31 & 47 & 52 & 46 & 6 & na \\
\hline 31 & Boston College (Carroll) & 43 & 35 & 14 & 53 & 32.5 & 26 & 6.5 & na \\
\hline 31 & Boston University & 47 & 46 & 47 & 1 & 31 & 19 & 12 & na \\
\hline 31 & Brigham Young (Marriott) & 45 & 36 & 52 & 30 & 47.5 & 45 & 2.5 & na \\
\hline 31 & Case Western (Weatherhead) & 26 & 58 & 62 & 40 & 54 & 28 & 26 & na \\
\hline 31 & Georgia (Terry) & 57 & 26 & 22 & 33 & 29 & 58 & -29 & na \\
\hline 31 & Georgia Tech (DuPree) & 59 & 33 & 18 & 46 & 40.5 & 30 & 10.5 & na \\
\hline 31 & Illinois -- Urbana-Champaign & 46 & 40 & 27 & 48 & 45.5 & 38 & 7.5 & na \\
\hline 31 & Iowa (Tippie) & 40 & 42 & 39 & 51 & 50 & 39 & 11 & na \\
\hline 31 & Michigan State (Broad) & 51 & 47 & 15 & 37 & 37.5 & 43 & -5.5 & na \\
\hline 31 & Minnesota (Caarlson) & 30 & 32 & 37 & 36 & 27 & 40 & -13 & na \\
\hline 31 & Ohio State (Fisher) & 41 & 24 & 50 & 22 & 28 & 29 & -1 & na \\
\hline 31 & Penn State (Smeal) & 65 & 44 & 30 & 17 & 40.5 & 41 & -0.5 & na \\
\hline
\end{tabular}




\begin{tabular}{|l|l|l|}
\hline 56 & -21 & na \\
\hline
\end{tabular}

Table 2: Business Schools Ranked by Inputs (continued)

\begin{tabular}{|c|c|c|c|c|c|c|c|c|c|}
\hline $\begin{array}{c}\text { BW } \\
\text { Rank }\end{array}$ & School Name & $\mathbf{f} / \mathbf{s}$ & gmat & \%reject & end/stud & Input & Input-pc & Difference & Difference-pc \\
\hline 31 & Southern Methodist (Cox) & 27 & 28 & 42 & 14 & 21 & 42 & -21 & na \\
\hline 31 & Thunderbird & 1 & 63 & 65 & 62 & 58 & 25 & 33 & na \\
\hline 31 & UC Irvine (Merage) & 11 & 29 & 41 & 64 & 32.5 & 62 & -29.5 & na \\
\hline 31 & Wake Forest (Babcock) & 10 & 53 & 56 & 44 & 47.5 & 48 & -0.5 & na \\
\hline 31 & Washington - Seattle & 53 & 19 & 32 & 26 & 26 & 27 & -1 & na \\
\hline 31 & Wisconsin - Madison & 56 & 30 & 16 & 12 & 23 & 24 & -1 & na \\
\hline 51 & Arizona (Eller) & 62 & 45 & 57 & 45 & 62.5 & 57 & 5.5 & na \\
\hline 51 & SUNY - Buffalo & 28 & 62 & 60 & 59 & 62.5 & 60 & 2.5 & na \\
\hline 51 & Connecticut & 31 & 51 & 48 & 57 & 55.5 & 49 & 6.5 & na \\
\hline 51 & Florida (Warrington) & 33 & 23 & 33 & 23 & 22 & 23 & -1 & na \\
\hline 51 & Florida International & 63 & 65 & 36 & 58 & 65 & 65 & 0 & na \\
\hline 51 & Fordham & 19 & 60 & 43 & 65 & 55.5 & 54 & 1.5 & na \\
\hline 51 & George Washington & 32 & 52 & 45 & 60 & 57 & 47 & 10 & na \\
\hline 51 & Pepperdine (Seaver) & 8 & 49 & 58 & 61 & 51 & 53 & -2 & na \\
\hline 51 & Pittsburgh (Katz) & 42 & 57 & 51 & 54 & 60 & 55 & 5 & na \\
\hline 51 & South Carolina (Darla Moore) & 60 & 54 & 64 & 25 & 59 & 61 & -2 & na \\
\hline 51 & Syracuse (Whitman) & 50 & 64 & 59 & 35 & 61 & 64 & -3 & na \\
\hline 51 & Tennessee - Knoxville & 64 & 59 & 40 & 20 & 53 & 59 & -6 & na \\
\hline 51 & Texas A\&M (Mays) & 58 & 48 & 20 & 21 & 35 & 44 & -9 & na \\
\hline 51 & Tulane (Freeman) & 52 & 34 & 55 & 27 & 49 & 52 & -3 & na \\
\hline 51 & William and Mary (Mason) & 54 & 61 & 63 & 34 & 64 & 63 & 1 & na \\
\hline
\end{tabular}

Note: $\quad$ See Table 1. The Input column comes by an arithmetic unweighted average of the $\mathrm{f} / \mathrm{s}, \mathrm{gmat}$, \%reject , and end/stud columns with a ranking of the resulting average numbers from 1 to 65 , with ties getting an average of the respective rankings. The Input-pc column provides the ranking based on the weighted first principal component of the $\mathrm{f} / \mathrm{s}, \mathrm{gmat}$, \% reject, and end/stud variables with weights on the normalized values of $-0.3682,0.6348,0.5847$, and 0.3456, respectively. The Difference column measures the difference between the Input (column 7) and the Input-pc (column 8) rankings. The Difference-pc column measures the difference between the BW Ranking (column 1) and the Input-pc (column 9) rankings. Thus, in the difference columns 9 and 10, a positive number means an improvement in ranking relative to the Output and Business Week rankings, respectively. For example, Indiana falls 19 positions from the Business Week to the Input-pc rankings, but improves 6 positions from the Input to the Input-pc rankings. Spearman rank correlations between the Input-pc ranking and our faculty-student ratio $(f / s)$, the GMAT score (gmat), the rejection percentage (\%reject), the endowment per student (end/stud), and the overall input (Input) rankings equal $0.54,0.84,0.75,0.38$, and 0.86 , respectively. The higher correlations for the rankings based on the GMAT scores and rejection percentages probably echo the MBA-program-specific information contained in those two variables. That is, the faculty-student and endowment-student ratios incorporate school-wide rather than MBA-program-specific information. Nonetheless, the overall input ranking correlation nearly matches the correlations for the rankings based on rejection percentages and GMAT scores. 
Table 3: Business Schools Ranked by Outputs and Inputs

\begin{tabular}{|c|c|c|c|c|c|c|c|}
\hline $\begin{array}{c}\text { BW } \\
\text { Rank }\end{array}$ & School Name & Outputs & Inputs & Combined & Combined-pc & Difference & Difference-pc \\
\hline 1 & Northwestern (Kellog) & 17 & 4.5 & 4 & 6 & -2 & -5 \\
\hline 2 & Chicago & 34.5 & 11.5 & 14 & 9 & 5 & -7 \\
\hline 3 & Pennsylvania (Wharton) & 1 & 6 & 1 & 4 & -3 & -1 \\
\hline 4 & Stanford & 39.5 & 2 & 8 & 2 & 6 & 2 \\
\hline 5 & Harvard & 27 & 1 & 3 & 1 & 2 & 4 \\
\hline 6 & Michigan (Ross) & 32 & 9 & 13 & 13 & 0 & -7 \\
\hline 7 & Cornell (Johnson) & 39.5 & 13 & 16 & 18 & -2 & -11 \\
\hline 8 & Columbia & 30.5 & 3 & 6.5 & 5 & 1.5 & 3 \\
\hline 9 & MIT (Sloan) & 2 & 7 & 2 & 3 & -1 & 6 \\
\hline 10 & Dartmouth (Tuck) & 21 & 4.5 & 5 & 7 & -2 & 3 \\
\hline 11 & Duke (Fuqua) & 9 & 14 & 10 & 14 & -4 & -3 \\
\hline 12 & Virginia (Darden) & 5.5 & 11.5 & 9 & 15 & -6 & -3 \\
\hline 13 & NYU (Stern) & 25 & 17 & 17 & 12 & 5 & 1 \\
\hline 14 & UCLA (Anderson) & 30.5 & 15 & 15 & 11 & 4 & 3 \\
\hline 15 & Carnegie Mellon (Tepper) & 21 & 25 & 23.5 & 16 & 7.5 & -1 \\
\hline 16 & UNC (Kenan-Flager) & 24 & 39 & 34.5 & 37 & -2.5 & -21 \\
\hline 17 & UC Berkeley (Haas) & 16 & 10 & 11 & 10 & 1 & 7 \\
\hline 18 & Indiana (Kelley) & 10.5 & 43 & 31.5 & 32 & -0.5 & -14 \\
\hline 19 & Texas - Austin (McCombs) & 43.5 & 18 & 23.5 & 24 & -0.5 & -5 \\
\hline 20 & Emory (Goizueta) & 33 & 20 & 21.5 & 20 & 1.5 & 0 \\
\hline 21 & Purdue (Krannert) & 7.5 & 37.5 & 26 & 23 & 3 & -2 \\
\hline 22 & Yale & 18.5 & 8 & 6.5 & 8 & -1.5 & 14 \\
\hline 23 & Washington (Olin) & 18.5 & 24 & 19 & 30 & -11 & -7 \\
\hline 24 & Notre Dame (Mendoza) & 23 & 30 & 28 & 33 & -5 & -9 \\
\hline 25 & Georgetown (McDonough) & 7.5 & 44 & 30 & 25 & 5 & 0 \\
\hline 26 & Babson (Olin) & 60.5 & 42 & 55.5 & 54 & 1.5 & -28 \\
\hline 27 & Southern California (Marshall) & 60.5 & 19 & 39 & 26 & 13 & 1 \\
\hline 28 & Maryland (Smith) & 42 & 45.5 & 41 & 36 & 5 & -8 \\
\hline 29 & Rochester (Simon) & 4 & 16 & 12 & 19 & -7 & 10 \\
\hline 30 & Vanderbilt (Owen) & 37 & 35 & 38 & 49 & -11 & -19 \\
\hline 31 & Arizona State (Cary) & 45 & 52 & 51 & 47 & 4 & na \\
\hline 31 & Boston College (Carroll) & 48.5 & 32.5 & 42 & 40 & 2 & na \\
\hline 31 & Boston University & 37 & 31 & 37 & 21 & 16 & na \\
\hline 31 & Brigham Young (Marriott) & 5.5 & 47.5 & 31.5 & 38 & -6.5 & na \\
\hline 31 & Case Western (Weatherhead) & 41 & 54 & 49 & 39 & 10 & na \\
\hline 31 & Georgia (Terry) & 64 & 29 & 54 & 58 & -4 & na \\
\hline 31 & Georgia Tech (DuPree) & 50 & 40.5 & 45 & 50 & -5 & na \\
\hline 31 & Illinois -- Urbana-Champaign & 58 & 45.5 & 55.5 & 42 & 13.5 & na \\
\hline 31 & Iowa (Tippie) & 37 & 50 & 43 & 45 & -2 & na \\
\hline 31 & Michigan State (Broad) & 10.5 & 37.5 & 27 & 41 & -14 & na \\
\hline 31 & Minnesota (Caarlson) & 12 & 27 & 21.5 & 29 & -7.5 & na \\
\hline 31 & Ohio State (Fisher) & 13 & 28 & 25 & 22 & 3 & na \\
\hline 31 & Penn State (Smeal) & 34.5 & 40.5 & 40 & 34 & 6 & na \\
\hline 31 & Rice (Jones) & 55 & 35 & 45 & 52 & -7 & na \\
\hline
\end{tabular}


Table 3: Business Schools Ranked by Outputs and Inputs (continued)

\begin{tabular}{|c|c|c|c|c|c|c|c|}
\hline $\begin{array}{c}\text { BW } \\
\text { Rank }\end{array}$ & School Name & Outputs & Inputs & Combined & Combined-pc & Difference & Difference-pc \\
\hline 31 & Southern Methodist (Cox) & 46 & 21 & 29 & 48 & -19 & na \\
\hline 31 & Thunderbird & 59 & 58 & 61 & 35 & 26 & na \\
\hline 31 & UC Irvine (Merage) & 57 & 32.5 & 45 & 64 & -19 & na \\
\hline 31 & Wake Forest (Babcock) & 14 & 47.5 & 33 & 44 & -11 & na \\
\hline 31 & Washington - Seattle & 3 & 26 & 18 & 17 & 1 & na \\
\hline 31 & Wisconsin - Madison & 29 & 23 & 20 & 27 & -7 & na \\
\hline 51 & Arizona (Eller) & 15 & 62.5 & 47 & 55 & -8 & na \\
\hline 51 & SUNY - Buffalo & 48.5 & 62.5 & 60 & 62 & -2 & na \\
\hline 51 & Connecticut & 56 & 55.5 & 59 & 57 & 2 & na \\
\hline 51 & Florida (Warrington) & 51 & 22 & 36 & 28 & 8 & na \\
\hline 51 & Florida International & 63 & 65 & 65 & 65 & 0 & na \\
\hline 51 & Fordham & 54 & 55.5 & 58 & 56 & 2 & na \\
\hline 51 & George Washington & 43.5 & 57 & 52.5 & 43 & 9.5 & na \\
\hline 51 & Pepperdine (Seaver) & 65 & 51 & 62 & 60 & 2 & na \\
\hline 51 & Pittsburgh (Katz) & 27 & 60 & 52.5 & 46 & 6.5 & na \\
\hline 51 & South Carolina (Darla Moore) & 62 & 59 & 64 & 63 & 1 & na \\
\hline 51 & Syracuse (Whitman) & 21 & 61 & 50 & 51 & -1 & na \\
\hline 51 & Tennessee - Knoxville & 53 & 53 & 57 & 59 & -2 & na \\
\hline 51 & Texas A\&M (Mays) & 27 & 35 & 34.5 & 31 & 3.5 & na \\
\hline 51 & Tulane (Freeman) & 47 & 49 & 48 & 53 & -5 & na \\
\hline 51 & William and Mary (Mason) & 52 & 64 & 63 & 61 & 2 & na \\
\hline
\end{tabular}

Note: $\quad$ See Table 1. The Combined column comes by an arithmetic unweighted average of the outputs and inputs columns with a ranking of those average numbers from 1 to 65. The Combined-pc column provides the ranking based on the weighted first principal component of the gains, jobs, f/s, gmat, \%reject, and end/stud variables with weights on the normalized values of $0.1201,0.4988,-0.2928,0.5431,0.5117$, and 0.3071 , respectively. The Difference column measures the difference between the Combined (column 5) and the Combined-pc (column 6) rankings. The Differencepc column measures the difference between the Business Week (column 1) and the Combined-pc (column 6) rankings. Thus, in the difference columns 7 and 8, a positive number means an improvement in ranking relative to the Combined and Business Week rankings, respectively. For example, Chicago improves 5 positions from the Combined ranking to the Combined-pc ranking, and then falls 7 positions from the Business Week ranking to the Combined-pc ranking. Spearman rank correlation between the Output, Input, and Combined rankings and the Combined-pc ranking both equals $0.62,0.86$, and 0.92 . 
APPENDIX:

Table A1: Business School Data

\begin{tabular}{|c|c|c|c|c|c|c|c|c|c|}
\hline BW Rank & School Name & Gain & jobs & $f / s$ & gmat & \%reject & end/stud & $\%$ male & $\% U S$ \\
\hline & Tier 1: Top 30 Averages & 28,869 & 1.4173 & 0.1424 & 680 & 67 & 235,919 & 72 & 69 \\
\hline & Tier 2: Second 20 Averages & 28,615 & 1.0264 & 0.2176 & 645 & 54 & 177,131 & 73 & 70 \\
\hline & Tier 3: Last 15 Averages & 24,400 & 0.9552 & 0.2321 & 614 & 45 & 82,839 & 70 & 66 \\
\hline 1 & Northwestern (Kellog) & 27,450 & 1.8 & 0.06941 & 700 & 77 & 203,765 & 71 & 71 \\
\hline 2 & Chicago & 23,384 & 1.7 & 0.06820 & 695 & 77 & 105,228 & 74 & 68 \\
\hline 3 & Pennsylvania (Wharton) & 34,662 & 2.1 & 0.12931 & 713 & 84 & 222,591 & 67 & 58 \\
\hline 4 & Stanford & 18,243 & 2.0 & 0.14662 & 711 & 90 & 702,573 & 65 & 70 \\
\hline 5 & Harvard & 22,925 & 2.4 & 0.10542 & 707 & 87 & 975,610 & 66 & 68 \\
\hline 6 & Michigan (Ross) & 24,366 & 1.6 & 0.08450 & 692 & 65 & 134,646 & 69 & 64 \\
\hline 7 & Cornell (Johnson) & 27,208 & 1.2 & 0.11371 & 673 & 64 & 187,291 & 72 & 72 \\
\hline 8 & Columbia & 23,980 & 1.7 & 0.10297 & 706 & 85 & 167,850 & 64 & 70 \\
\hline 9 & MIT (Sloan) & 32,524 & 2.2 & 0.12524 & 697 & 80 & 530,507 & 69 & 67 \\
\hline 10 & Dartmouth (Tuck) & 27,789 & 1.6 & 0.11900 & 704 & 81 & 336,000 & 75 & 70 \\
\hline 11 & Duke (Fuqua) & 32,311 & 1.4 & 0.09920 & 707 & 63 & 111,138 & 71 & 69 \\
\hline 12 & Virginia (Darden) & 35,237 & 1.2 & 0.11811 & 680 & 62 & 408,680 & 79 & 74 \\
\hline 13 & NYU (Stern) & 26,208 & 1.5 & 0.16098 & 700 & 78 & 67,122 & 64 & 72 \\
\hline 14 & UCLA (Anderson) & 24,740 & 1.6 & 0.09528 & 705 & 75 & 57,226 & 67 & 73 \\
\hline 15 & Carnegie Mellon (Tepper) & 31,636 & 1.2 & 0.17758 & 691 & 72 & 12,942 & 80 & 73 \\
\hline 16 & UNC (Kenan-Flager) & 33,670 & 1.0 & 0.16509 & 652 & 53 & 111,322 & 71 & 72 \\
\hline 17 & UC Berkeley (Haas) & 29,317 & 1.5 & 0.14715 & 701 & 83 & 133,966 & 73 & 67 \\
\hline 18 & Indiana (Kelley) & 35,428 & 1.1 & 0.23609 & 644 & 67 & 61,492 & 74 & 71 \\
\hline 19 & Texas - Austin (McCombs) & 28,508 & 1.0 & 0.12422 & 670 & 57 & 130,990 & 80 & 74 \\
\hline 20 & Emory (Goizueta) & 26,437 & 1.3 & 0.17198 & 680 & 63 & 128,599 & 66 & 67 \\
\hline 21 & Purdue (Krannert) & 32,006 & 1.5 & 0.22750 & 667 & 56 & 107,029 & 82 & 62 \\
\hline 22 & Yale & 32,181 & 1.2 & 0.14010 & 696 & 75 & 662,687 & 66 & 77 \\
\hline 23 & Washington (Olin) & 32,759 & 1.2 & 0.12297 & 649 & 46 & 263,123 & 79 & 66 \\
\hline 24 & Notre Dame (Mendoza) & 35,063 & 1.0 & 0.25049 & 657 & 51 & 379,506 & 72 & 71 \\
\hline 25 & Georgetown (McDonough) & 32,908 & 1.4 & 0.20945 & 662 & 59 & 48,815 & 69 & 60 \\
\hline 26 & Babson (Olin) & 22,378 & 0.8 & 0.16641 & 630 & 41 & 169,176 & 71 & 61 \\
\hline 27 & Southern California (Marshall) & 20,001 & 0.8 & 0.15108 & 685 & 64 & 109,432 & 75 & 79 \\
\hline 28 & Maryland (Smith) & 28,715 & 1.0 & 0.18394 & 651 & 62 & 34,583 & 66 & 61 \\
\hline 29 & Rochester (Simon) & 34,991 & 1.3 & 0.12475 & 665 & 63 & 138,614 & 74 & 58 \\
\hline 30 & Vanderbilt (Owen) & 29,055 & 1.1 & 0.13529 & 622 & 32 & 375,066 & 80 & 72 \\
\hline 31 & Arizona State (Cary) & 27,827 & 1.0 & 0.32208 & 649 & 60 & 78,961 & 82 & 73 \\
\hline 31 & Boston College (Carroll) & 28,572 & 0.7 & 0.20742 & 653 & 70 & 55,897 & 65 & 77 \\
\hline 31 & Boston University & 32,227 & 0.9 & 0.22704 & 637 & 49 & $1,108,844$ & 60 & 70 \\
\hline 31 & Brigham Young (Marriott) & 39,808 & 1.2 & 0.21057 & 653 & 46 & 131,792 & 79 & 86 \\
\hline 31 & Case Western (Weatherhead) & 28,576 & 1.1 & 0.15295 & 600 & 31 & 110,440 & 62 & 67 \\
\hline 31 & Georgia (Terry) & 9,610 & 0.6 & 0.27079 & 663 & 64 & 125,299 & 73 & 69 \\
\hline 31 & Georgia Tech (DuPree) & 24,940 & 1.0 & 0.28294 & 655 & 66 & 84,233 & 84 & 59 \\
\hline 31 & Illinois -- Urbana-Champaign & 21,221 & 0.9 & 0.22350 & 649 & 62 & 76,409 & 73 & 52 \\
\hline 31 & Iowa (Tippie) & 28,192 & 1.1 & 0.19180 & 645 & 55 & 58,833 & 68 & 55 \\
\hline
\end{tabular}


Table A1: Business School Data (continued)

\begin{tabular}{|c|c|c|c|c|c|c|c|c|c|}
\hline BW Rank & School Name & Gain & jobs & $f / s$ & gmat & \%reject & end/stud & \%male & $\% U S$ \\
\hline 31 & Michigan State (Broad) & 41,672 & 1.1 & 0.24494 & 637 & 68 & 117,079 & 68 & 65 \\
\hline 31 & Minnesota (Caarlson) & 31,409 & 1.5 & 0.16099 & 656 & 56 & 117,231 & 80 & 66 \\
\hline 31 & Ohio State (Fisher) & 33,624 & 1.2 & 0.20330 & 665 & 47 & 147,698 & 75 & 66 \\
\hline 31 & Penn State (Smeal) & 31,925 & 1.0 & 0.52929 & 643 & 61 & 176,710 & 78 & 65 \\
\hline 31 & Rice (Jones) & 24,884 & 0.8 & 0.17746 & 625 & 48 & 417,804 & 69 & 81 \\
\hline 31 & Southern Methodist (Cox) & 28,972 & 0.8 & 0.15345 & 661 & 54 & 218,274 & 75 & 78 \\
\hline 31 & Thunderbird & 24,565 & 0.6 & 0.06067 & 587 & 18 & 18,004 & 74 & 57 \\
\hline 31 & UC Irvine (Merage) & 17,522 & 1.0 & 0.11208 & 659 & 55 & 10,158 & 68 & 71 \\
\hline 31 & Wake Forest (Babcock) & 32,209 & 1.3 & 0.11041 & 630 & 40 & 104,705 & 74 & 82 \\
\hline 31 & Washington - Seattle & 31,562 & 1.8 & 0.25000 & 677 & 60 & 136,546 & 74 & 77 \\
\hline 31 & Wisconsin - Madison & 32,989 & 1.0 & 0.25941 & 658 & 68 & 247,699 & 70 & 78 \\
\hline 51 & Arizona (Eller) & 35,161 & 1.1 & 0.34979 & 639 & 38 & 97,904 & 68 & 59 \\
\hline 51 & SUNY - Buffalo & 31,003 & 0.4 & 0.15385 & 595 & 34 & 23,866 & 61 & 63 \\
\hline 51 & Connecticut & 27,418 & 0.4 & 0.16414 & 630 & 48 & 32,654 & 64 & 68 \\
\hline 51 & Florida (Warrington) & 20,342 & 1.1 & 0.16468 & 666 & 59 & 141,638 & 81 & 80 \\
\hline 51 & Florida International & 12,028 & 0.6 & 0.35978 & 525 & 56 & 32,270 & 96 & 42 \\
\hline 51 & Fordham & 25,986 & 0.7 & 0.12859 & 598 & 53 & 995 & 55 & 71 \\
\hline 51 & George Washington & 23,486 & 1.4 & 0.16452 & 630 & 51 & 21,800 & 64 & 64 \\
\hline 51 & Pepperdine (Seaver) & 7,295 & 0.5 & 0.10320 & 631 & 38 & 21,641 & 73 & 74 \\
\hline 51 & Pittsburgh (Katz) & 27,320 & 1.4 & 0.20355 & 620 & 47 & 52,192 & 71 & 51 \\
\hline 51 & South Carolina (Darla Moore) & 23,733 & 0.6 & 0.28953 & 627 & 25 & 137,061 & 69 & 75 \\
\hline 51 & Syracuse (Whitman) & 26,186 & 2.1 & 0.24232 & 568 & 35 & 119,362 & 68 & 45 \\
\hline 51 & Tennessee - Knoxville & 24,419 & 0.9 & 0.37855 & 600 & 55 & 151,420 & 67 & 83 \\
\hline 51 & Texas A\&M (Mays) & 26,751 & 1.4 & 0.27974 & 637 & 65 & 150,079 & 72 & 80 \\
\hline 51 & Tulane (Freeman) & 29,669 & 0.7 & 0.24932 & 654 & 40 & 135,501 & 73 & 73 \\
\hline 51 & William and Mary (Mason) & 25,199 & 0.9 & 0.25000 & 597 & 31 & 124,207 & 73 & 59 \\
\hline
\end{tabular}

Note: The data include two outputs - gain and jobs - and six inputs - $f / s$, gmat, end/stud, \%male, and \%US. The outputs measure the value added and the adjusted number of job offers, respectively. The inputs measure the faculty-student ratio, the GMAT score, the percentage rejection rate, the endowment-student ratio, the percentage male applicants, and the percentage US applicants. See the text in the appendix for more details. The data come from the following web site: http://www.businessweek.com/bschools/index.html.

\section{Outputs and Inputs Definitions}

Output 1: $\quad$ gain = average post MBA salary + annuity value of first year compensation average pre MBA salary - 2 years times the annuity value of tuition and fee - including room \& board

where

(1) annuity value of first year compensation includes average signing bonus and average other compensation; interest rate is equal to 5 percent for the next 25 years 
(2) 2 years *annuity value of tuition and fee includes room \& board (that is, Annual Out-of-State Tuition*probability(out-of-state)+ Annual In-State Tuition*[1-Probability(out of state)]+Room \& Board) and also making annuity values by using 5-percent interest rate for the next 25 years

Output 2: $\quad$ jobs = job offers by graduation

$=$ Average Job Offers per student $*$ the percentage of graduates with job offers

Input 1: $\quad f / s=$ faculty- student ratio

$=$ (resident faculty +0.5 visiting faculty) $/$ (full time student +0.5 part time student)

Input 2: $\quad$ gmat = average GMAT score

Input 3: $\quad \%$ reject $=100-$ selectivity (applicants accepted), unit: percentage

Input 4: $\quad$ end/stud $=1998 / 99$ school budget $/$ enrollment where enrollment $=$ full time student $+0.5 *$ part time student

Input 5: $\quad \%$ male $=100-$ female enrollment percentage, unit: percentage

Input 6: $\% U S=100-$ international enrollment percentage, unit: percentage

Source: $\quad$ http://www.businessweek.com/bschools/index.html. 